\title{
PENGEMBANGAN WISATA BERBASIS SYARIAH (HALAL TOURISM) DI KOTA BIMA
}

\author{
Hadi Santoso \\ Administrasi Negara, Sekolah Tinggi Ilmu Sosial dan Ilmu Politik (STISIP) Mbojo ${ }^{1)}$ \\ Email : smbima01@gmail.com \\ Adi Hidayat Argubi \\ Administrasi Negara, Sekolah Tinggi Ilmu Sosial dan Ilmu Politik (STISIP) Mbojo ${ }^{2)}$ \\ Email : adi.hidayat@stisipbima.ac.id
}

\begin{abstract}
The study entitles "Sharia (Halal Tourism) Tourism Development in the Bima Town" has the objective to analyze the specific characteristics possessed by the town of Bima in supporting to tourism development program based on sharia (halal tourism) as it is intrinsically supported by the local wisdom potentials of Bima people. The approach used in this study is a participatory approach. This research is conducted in the city of Bima by using a research data collection techniques, including: participatory observation, unstructured interviews and documentation study. Data are analyzed by using qualitative analysis through three stages, namely, data reduction, data display and a conclusion (verification) by using analytical approach: FGD, RRA, PRA and SWOT analysis by means of mapping sharia-based tourism development (halal tourism) in the town of Bima. The results of the assessment rating of the potential attractions of sharia in Bima town is largely stated that the city of Bima has the potential and readiness to mnjadi tourist destinations sharia with different potentials, such as natural attractions, culture, infrastructure and tourism infrastructure, as well as the support of local governments and local communities of Bima town. Bima town has a potential varieties become one of the sharia tourist destinations because of strong influence of Islamic history and customs of Islam, as well as natural tourist attractions, cultural, religious and special interests tourists. Bima town has already been nearly ready to support the development of sharia-based tourism, such as hotels sharia, Islamic banks, pawnshops sharia, as well as supported by typical Muslim cultures and social acceptance.
\end{abstract}

Keywords: Halal Tourism

\section{ABSTRAK}

Penelitian dengan judul "Pengembangan Wisata Berbasis Syariah (Halal Tourism) Di Kota Bima" ini memiliki tujuan penelitian ini adalah menganalisis karakteristik spesifik yang dimiliki Kota Bima dalam mendukung pengembangan wisata berbasis syariah (halal tourism) di Kota Bima yang didukung dengan potensi kearifan lokal Bima, mengkaji permasalahan yang dihadapi Kota Bima dalam pengembangan wisata berbasis syariah (halal tourism), serta menganalisis potensi pengembangan wisata berbasis syariah (halal tourism) di Kota Bima yang didukung dengan potensi kearifan lokal Bima. Untuk mencapai tujuan tersebut di atas, penelitian ini mengunakan metode deskriptif. Pendekatan yang digunakan dalam penelitian ini adalah pendekatan partisipatif. Penelitian ini dilakukan di Kota Bima dengan teknik pengumpulan data penelitian antara lain: observasi partisipatif, wawancara tak terstruktur dan studi dokumentasi. Teknik analisis data menggunakan analisis kualitatif melalui tiga tahapan, yaitu reduksi data, display data dan pengambilan kesimpulan (verifikasi) dengan pendekatan menggunakan analisis FGD, RRA, PRA dan analisis SWOT pemetaan pengembangan wisata berbasis syariah (halal tourism) di Kota Bima. Hasil penilaian wisatawan terhadap potensi objek wisata syariah di Kota Bima sebagaian besar menyatakan bahwa Kota Bima memiliki potensi dan kesiapan untuk mnjadi destinasi wisata syariah dengan berbagai potensi yang 
dimiliki, seperti objek wisata alam, wisata budaya, sarana dan prasarana pariwisata, serta dukungan dari pemerintah daerah dan masyarakat lokal Kota Bima. Kota Bima memiliki beragam potensi untuk menjadi salah satu destinasi wisata syariah yang strategis karena sejarah ke islaman yang sangat kuat, dan adat istiadat berpegang teguh dengan islam, serta atraksi wisata alam, budaya, religi serta minatkhusus. Kota Bima sudah memiliki kelengkapan untuk menunjang pengembangan wisata berbasis syariah seperti hotel syariah, bank syariah, pegadaian syariah serta didukung oleh kultur budaya khas muslim dan penerimaan masyarakat.

\section{Kata Kunci: Halal Tourism}

\section{PENDAHULUAN}

Kementerian Pariwisata menyatakan bahwa "agar pengembangan wisata syariah lebih optimal, pemerintah menetapkan tiga provinsi sebagai prioritas pengembangan, yakni Sumatra Barat, Nusa Tenggara Barat (NTB), dan Nanggroe Aceh Darussalam. Ketiga daerah itu, katanya, sudah memiliki kelengkapan untuk menunjang pengembangan wisata berbasis syariah. Tinggal bagaimana strategi promosi untuk meningkatkan minat asing, serta mempermudah akses transportasi. Pemerintah menargetkan kunjungan wisman tahun ini mencapai 12 juta orang dan meningkat hingga 20 juta orang pada 2019 atau tumbuh rata-rata 16\% per tahun. Sementara tahun lalu, jumlah wisman yang mengunjungi Indonesia hanya 9,4 juta orang (Bisnis.com, 2015).

Nusa Tenggara Barat (NTB) pada umumnya dan Kota Bima pada khususnya memiliki mayoritas penduduk Indonesia adalah muslim, jadi dengan adanya wisata syariah juga dapat menjaga eksistensi NTB dan Kota Bima sebagai daerah dengan mayoritasmuslim.Dengan dilahirkannya ide wisata syariah, diharapkan NTB dan Kota Bima dapat memfasilitasi wisatawan dari dalam negeri dan juga mancanegara, khususnya Timur Tengah. Pemerintah memprioritaskan kunjungan wisman dari negara-negara kawasan Asean, Timur Tengah dan China untuk mengejar target kunjungan 20 juta orang pada 2019.Menteri Pariwisata Arief Yahya mengungkapkan tiga kawasan itu dipilih karena dekat secara geografis dan historis, sehingga memungkinkan mempercepat realisasi target kunjungan wisatawan mancanegara (wisman)."Kami prioritaskan wisman dari negara-negara di kawasan Asean, Timur Tengah.Termasuk juga China karena potensinya sangat besar," (Bisnis.com, 2015).

Kota Bima sudah memiliki kelengkapan untuk menunjang pengembangan wisata berbasis syariah seperti hotel syariah, bank syariah, pegadaian syariah serta didukung oleh kultur budaya khas muslim dan penerimaan masyarakat. Tinggal bagaimana rumusan model pengembangannya, strategi promosi untuk meningkatkan minat asing, serta mempermudah akses transportasi dan peningkatan kualitas objek. Kota Bima memiliki potensi sebagai destinasi transit tourism karena berada pada jalur emas wisata Indonesia, yaitu jalur Bali-Lombok dan Lombok - Labuan Bajo Flores dengan Pulau Komodonya. Potensi pengembangan wisata syariah (halal tourism) menjadi salah satu alternatif strategi peningkatan sumber Pendapatan Asli Daerah Kota Bima yang masih sangat kecil, yaitu 6,6 Milyar untuk semester I di Tahun 2016 (Tambora New.com, 2016) serta peningkatan ekonomi masyarakat melalui aktivitas wisata dan wisata syariah kreatif lainnya yang berkembang selaras perkembangan wisata berbasis syariah. Oleh karena itu, identifikasi dan pemetaan masalah terkait pengembangan wisata syariah (halal tourism) harus dilakukan untuk menentukan langkah yang tepat 
dalam pengembangan wisata berbasis syariah di Kota Bima.

Kota Bima sebagai salah satu kota di Nusa Tenggara Barat (NTB) yang dikenal dengan kota seribu masjid dan umat muslim mayoritas turut memberikan kontribusi keberhasilan pencapaian penghargaan World's Best Halal Honeymoon Destination dan World's Best Halal Tourism Destination bagi NTB. Di Kota Bima sendiri, salah satu cara pemerintah daerah untuk merealisasikan konsep wisata syariah, langkah utama yang mereka ambil adalah mendorong hotelhotel yang ada disana untuk menerapkan konsep syariah. Kota Bima juga mulai menerapkan konsep syariah dalam penataan hiburan. Seperti penataan tempat karaoke dan Bar yang ada. Pemerintah daerah juga berusaha memboomingkan wisata daerah yang ada di Kota Bima ini lewat pawai budaya. Yaitu dengan cara menggelar aneka ragam atraksi budaya dan hiburan semenarik mungkin dan meninggalkan kesan vulgar ataupun terbuka. Dengan cara seperti ini, pemerintah berharap para wisatawan akan merasakan sensasi yang berbeda ketika berlibur di Kota Bima yang terkenal dengan sebutan seribu masjid ini. Kota Bima ingin mengenalkan wisata alam dan budayanya melalui jalur wisata syariah dan tetap mengedepankan prinsip-prinsip islami.

\section{METODE PENELITIAN}

Penelitian ini mengunakan metode deskriptif. Pendekatan yang digunakan dalam penelitian ini adalah pendekatan partisipatif. Penelitian ini dilakukan di Kota Bima dengan teknik pengumpulan data penelitian antara lain: observasi partisipatif, wawancara tak terstruktur dan studi dokumentasi. Informan kunci dalam penelitian ini adalah Dinas Kebudayaan dan Pariwisata Kota Bima, PHRI Kota Bima, ASITA, Pengusaha Objek dan Atraksi Wisata yang kemudian menggelinding kepada informan kunci lain sesuai dengan kapasitas dan kompetensi menjawab permasalahan penelitian, yaitu stakeholders pariwisata kota Bima yang kompeten pada permasalahan penelitian. Teknik analisis data menggunakan analisis kualitatif melalui tiga tahapan, yaitu reduksi data, display data dan pengambilan kesimpulan (verifikasi) dengan pendekatan menggunakan analisis FGD, RRA, PRA dan analisis SWOT pemetaan pengembangan wisata berbasis syariah (halal tourism) di Kota Bima

\section{HASIL DAN PEMBAHASAN Potensi Obyek Dan Daya Tarik Wisata Kota Bima}

Daya tarik wisata merupakan dasar dari pengembangan pariwisata, hal ini merupakan elemen penting dalam produk pariwisata. Tanpa adanya faktor daya tarik yang substansial, pariwisata yang berorientasi untuk kesenangan atau untuk berlibur tidak memungkinkan dikembangkan. Meskipun demikian masih ada peluang-peluanglain, misalnya saja perjalanan bisnis, dinas pemerintah, conferensi, keagamaan dan berbagai maksud perjalanan wisatalainnya. Pendekatan penting yang dapat dilakukan adalah mengkaitkan komponen dayatarik yang dimliki dengan kegiatan wisata yang mungkin dilakukan. Komponen tersebut secara tersendiri dapat saja merupakan sebuah daya tarik yang dapat dijual dan dikembangkan, sehingga daya tarik wisata perlu dievaluasi dan diidentifikasi untuk mempertimbangkan peluang kegiatan wisata yang dapat dikembangkan didaerah.

Untuk melakukan survey dan evaluasi dari daya tarik wisata, maka akan sangat penting untuk memahami jenis objek dan daya tarik yang perlu dipertimbangkan dalam pariwisata. Hal ini terutama dilakukan dalam fungsi analisis. Konsep umum dari jenis daya tarik yang telah lama dikenal adalah daya tarik alam yang biasanya berbentuk, pantai, danau, laut, iklim, hutan, lansekap alam, pemandangan dan 
bentuk- bentuk lainnya.Objek dan daya tarik wisata dapat dikelompokkan dengan berbagai cara.

Sistem umum dari pengelompokkan yang sering dipakai adalah:

1. Objek dan daya tarik alam, yang berbasiskan segala pada lingkunganalam.

2. Objek dan daya tarik budaya, yang berbasiskan pada kegiatan manusia.

3. Objek dan daya tarikk husus, yang biasanya dibuat secara khusus oleh manusia untuk menarik kunjungan wisatawan.

\section{Obyek Dan Daya TarikAlam}

Kota Bima berdiri di tepi Teluk Bima yang sangat tenang. Gunung mengurungnya dari tiga penjuru (timur, utara, dan selatan).Di sepanjang pesisir Teluk Bima terdapat daya tarik wisata bahari, sedangkan di sisi utara dan timur terdapat wisata tirta dan wisata alam lainnya.

Tabel 2.Obyek Daya Tarik Alam Kota Bima

\begin{tabular}{|c|l|l|c|c|}
\hline No & \multicolumn{1}{|c|}{$\begin{array}{c}\text { Nama Obyek } \\
\text { Wisata }\end{array}$} & Jenis Obyek Wisata & Kelurahan & Kecamatan \\
\hline 1 & Pantai Ni'u & Wisata Pantai/ Bahari & Dara & Rasanae Barat \\
\hline 2 & Pantai Lawata & Wisata Pantai/ Bahari & Dara & Rasanae Barat \\
\hline 3 & Pantai Kolo & Wisata Pantai/ Bahari & Kolo & Asakota \\
\hline 4 & Pantai Ule & Wisata Pantai/ Bahari & Melayu & Asakota \\
\hline 5 & Pantai So Ati & Wisata Pantai/ Bahari & Kolo & Asakota \\
\hline 6 & Pulau kambing & Wisata Pantai/ Bahari & & \\
\hline 7 & Pantai Amahami & Wisata Pantai/ Bahari & Dara & Rasanae Barat \\
\hline 8 & Diwu Monca & WisataTirta & Lampe & Rasanae Timur \\
\hline 9 & Lanco Gajah & Wisata Tirta & jati baru & Asakota \\
\hline 10 & Taman Ria & Wisata Alam & & \\
\hline
\end{tabular}

Sumber: Dinas Kebudayaan Dan Pariwisata, 2018

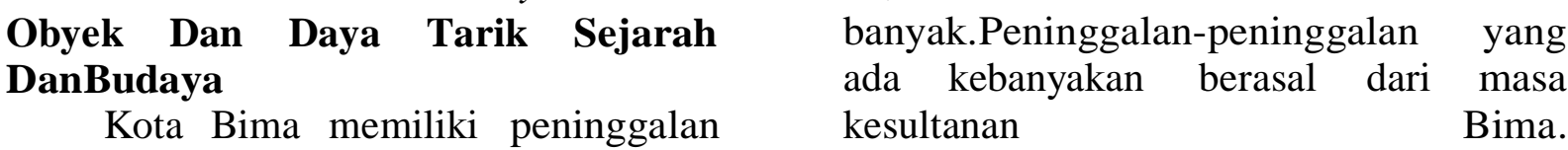
sejarah dan kepurbakalaan yang cukup

Tabel 3.Obyek Daya Tarik Budaya Kota Bima

\begin{tabular}{|c|l|c|c|c|}
\hline No & Nama Obyek Wisata & Jenis Obyek Wisata & Kelurahan & Kecamatan \\
\hline & Museum Asi & Paruga & Rasanae Barat \\
1 & Mbojo/Istana Bima & Wisata Budaya & & \\
\hline 2 & Masjid Sultan Salahudin & Wisata Budaya & Paruga & Rasanae Barat \\
\hline 3 & Makam Dana traha & Wisata Budaya & Dara & Rasanae Barat \\
\hline 4 & Benteng Asakota & Wisata Budaya & Kolo & Asakota \\
\hline 5 & Museum Samparaja & Wisata Budaya & Manggemaci & Mpunda \\
\hline 6 & Langgar Melayu Kuno & Wisata Budaya & Melayu & Asakota \\
\hline 7 & Mariam kuno Lela Mase & Wisata Budaya & Lelamase & Rasanae Timur \\
\hline 8 & Kampung Pandai Besi & & & \\
\hline 9 & Sentra Kerajinan Tenun & & & \\
\hline
\end{tabular}




\section{Potensi Amenitas (Infrastruktur}

Pendukung Pengembangan Wisata

Syariah: Jumlah Hotel, Resto/Kuliner)

Pada kenyataannya banyak sekali jenis akomodasi yang terdapat di suatu daerah. Meskipun terminologi dari berbagai jenis fasilitas akomodasi muncul namun batasan pasti sulit sekali untuk diidentifikasi. Untuk kepentingan survey, analisis dan perencanaan terminologi yang umumnya digunakan di Indonesia adalah berdasarkan klasifikasi hotel berbintang dan melati. Kota Bima memiliki cukup banyak hotel/penginapan/losmen baik berbintang maupun melati. Pada tahun 2018, tercatat ada 17 hotel/penginapan/losmen yang berorientasi tidak hanya pada satu fungsi saja.

Agen perjalanan wisata termasuk di dalamnya agen yang menawarkan program wisata lokal dan penanganan pelayanan kepada wisatawan merupakan sumbersumber informasi yang perlu dipertimbangkan. Pelayanan penjualan tiket penerbangan, kereta api, kapal laut dan bus, penyewaan kendaraan, reservasi hotel dan pelayanan wisata dalam maupun luar negeri merupakan faktor-faktor yang perlu untuk dikaji. iscepí

Pada beberapa daerah kompetensi pemandu wisata dalam menjelaskan objek dan daya tarik wisata, bahasa dan pengalaman merupakan masukan bagi dokumen perencanaan. Paket wisata yang ditawarkan perlu dievaluasi untuk melihat faktor tingkatan harga, program yang ditawarkan, kualitas pelayanan, kehandalan pelayanan dan keamanan perjalanan. Hal ini berguna bagi tim perencana untuk pendekatan yang dilakukan oleh pihak operator dalam melaksanakan usahanya. Peraturan mengenai agen perjalanan wisata dan pemandu wisata telah ditetapkan oleh pemerintah, baik pemerintah pusat maupun pemerintah daerah.

Data agen perjalanan wisata di Kota Bima yang tercatat pada Dinas Kebudayaan Dan Pariwisata sebagai pendukung pengembangan pariwisata daerah di Kota Bima dapat dilihat pada tabel berikut ini

Tabel 4.Daftar Agen Perjalanan Kota Bima

\begin{tabular}{|c|l|l|l|}
\hline N O & \multicolumn{1}{|c|}{ NAMA } & \multicolumn{1}{|c|}{ ALAMAT / NO. HP } & \multicolumn{1}{|c|}{ NAMA PEMILIK } \\
\hline 1 & Mulia & - & - \\
\hline 2 & PT. Fajar Bima & - & - \\
\hline 3 & $\begin{array}{l}\text { PT. Merpati Ticketing Distric } \\
\text { Bima }\end{array}$ & - & - \\
\hline 4 & PT. Lancar Jaya Travel agent & - & - \\
\hline 5 & PT. Man Jaya Executive & - & - \\
\hline 6 & Hai Travel & Jl. Sumbawa No 8 Kel. Paruga & H. A. Rahman, SE. \\
\hline 7 & PT. GSA Trans nusa & Jl. Sulawesi Kel. Paruga & Whindra \\
\hline 8 & PT. Kristal KW & - & - \\
\hline 9 & 2 Avira Travel & - & - \\
\hline 10 & Travel Bintang Timur & Jl. Gatot Subroto Kel. Sadia & Lafran Abdul Kahar \\
\hline 11 & $\begin{array}{l}\text { PT. Iskandaria Biro Umro dan } \\
\text { Haji }\end{array}$ & Jl. Mawar No 24 Kel. Sarae & Muh. Mutawali, MA. \\
\hline 12 & Travel Agent Zafira & $\begin{array}{l}\text { Jl. Gajah Mada No 21 Kel. } \\
\text { Monggonao }\end{array}$ & Fikri Rino Adi \\
\hline 13 & Travel Agent Sahra & $\begin{array}{l}\text { Jl. Soekarno Hatta Kel. } \\
\text { Rabangodu Utara }\end{array}$ & M. Saleh A. Gani \\
\hline
\end{tabular}


Fasilitas restoran, rumah makan, bar, penjualan makanan dan minuman memberi pola kepada pengembangan pariwisata daerah. Untuk mernuaskan permintaan wisatawan secara normal, maka daerah seharusnya memiliki kualitas makanan yang baik yang dapat ditawarkan kepada wisatawan. Makanan khas daerah yang menarik dapat merupakan daya tarik pendukung bagi wisatawan. Wisatawan yang berkunjung ke daerah akan memiliki pengalaman yang semakin baik bila makanan yang tersedia di daerah dapat memenuhi selera.Data Fasilitas rumah makan yang tercatat pada Dinas Kebudayaan Dan Pariwisata sebagai pendukung pengembangan pariwisata daerah di Kota Bima dapat dilihat pada tabel berikut ini:

Tabel 5.Daftar Rumah Makan Kota Bima

\begin{tabular}{|c|c|c|c|}
\hline NO & NAMA & ALAMAT / NO. HP & $\begin{array}{c}\text { JUMLAH KURSI } \\
\text { \& MEJA }\end{array}$ \\
\hline 1 & KFC & $\begin{array}{l}\text { Jl. Sultan Hasanuddin, Sarae, } \\
\text { Rasanae Barat }\end{array}$ & 26 Meja x 2 Kursi \\
\hline 2 & Srikandi & $\begin{array}{l}\text { Jl. Pahlawan Dara, Rasanae } \\
\text { Barat }\end{array}$ & 5 meja x 30 kursi \\
\hline 3 & RM. Arema Raya & $\begin{array}{l}\text { Jl. Sultan Hasanuddin, Sarae, } \\
\text { Rasanae Barat }\end{array}$ & 4 meja x 25 kursi \\
\hline 4 & RM. Anda & $\begin{array}{l}\text { Jl. Poros Lawata, Dara, } \\
\text { Rasanae Barat }\end{array}$ & 4 meja x 4 kursi \\
\hline 5 & RM. Purnama & $\begin{array}{l}\text { J1. Poros Lawata, Dara, } \\
\text { Rasanae Barat }\end{array}$ & 9 meja x 8 kursi \\
\hline 6 & RM. Mahkota Mawar & $\begin{array}{l}\text { Jl. Sulawesi, Dara, Rasanae } \\
\text { Barat }\end{array}$ & 4 meja $\times 8$ kursi \\
\hline 7 & RM. Takanajuo & Jl. Soekarno Hatta & 4 meja x 16 kursi \\
\hline 8 & RM. Beringin Indah & $\begin{array}{l}\text { Jl. Sultan Kaharudin, Paruga, } \\
\text { Rasanae Barat }\end{array}$ & 4 meja x 10 kursi \\
\hline 9 & RM. Surabaya & $\begin{array}{l}\text { Jl. Sultan Kaharudin, Paruga, } \\
\text { Rasanae Barat }\end{array}$ & 4 meja x 10 kursi \\
\hline 10 & RM. Pade Doang & $\begin{array}{l}\text { Jl. Martadinata, sarae, } \\
\text { Rasanae Barat }\end{array}$ & 5 meja x 20 kursi \\
\hline 11 & RM. Kediri & $\begin{array}{l}\text { Jl. Sultan Kaharuddin, } \\
\text { Paruga, Rasanae Barat }\end{array}$ & 4 meja x 16 kursi \\
\hline 12 & RM. Marem & $\begin{array}{l}\text { J1. Pahlawan Dara, Rasanae } \\
\text { Barat }\end{array}$ & 6 meja x 24 kursi \\
\hline 13 & RM. Jawa Asih & Kel. Paruga, Rasanae Barat & 3 meja x 12 kursi \\
\hline 14 & RM. Minang Raya & Kel. Paruga, Rasanae Barat & 3 meja x 12 kursi \\
\hline 15 & RM. Arema Santi & Jl. Gajah Mada & 12 meja x 32 kursi \\
\hline 16 & RM. Gurih & Jl. Ir. Sutami, Raba & 6 meja x 18 kursi \\
\hline 17 & RM. Singgalang & $\begin{array}{l}\text { Jl. ST. Hasanuddin, Sarae, } \\
\text { Rasanae Barat }\end{array}$ & - \\
\hline 18 & RM. Manalagi & Kompleks Pasar Raba, Raba & 4 meja x 16 kursi \\
\hline 19 & RM. Depot Kita & Jl. Tolo Bali & 3 meja x 12 kursi \\
\hline 20 & Lesehan Putri & Jl. Sukarno Hatta & - \\
\hline 21 & Aqilah & $\begin{array}{l}\text { Jl. Datuk Dibanta No.20 Pane } \\
\text { Rasanae Barat }\end{array}$ & 12 meja x 16 kursi \\
\hline 22 & Restu Ambarani & Jl. Anggur Rabadompu, Raba & 8 meja x 24 kursi \\
\hline 23 & Depot Prasmanan & Jl. Sukarno Hatta & - \\
\hline
\end{tabular}




\begin{tabular}{|c|l|l|c|}
\hline 24 & Benteng Takeshi & Jl. Jenderal Sudirman & - \\
\hline 25 & Lesehan Morodadi & Jl. Sukarno Hatta & - \\
\hline 26 & Arema Santi & Jl. Gajah Mada & 14 meja x 54 kursi \\
\hline 27 & Depot Celebes & Jl. Gajah Mada No. 23 & 5 meja x 8 kursi \\
\hline 28 & Depot Srikandi & Jl. Lombok & - \\
\hline 29 & Erni Sari & Jl. Sukarno Hatta & 5 meja x 20 kursi \\
\hline 30 & Minang Raya & Jl. Sukarno Hatta & 5 meja x 20 kursi \\
\hline 31 & Takeshi Bento & Jl. Jenderal Sudirman & - \\
\hline
\end{tabular}

Informasi pariwisata umumnya disediakan oleh pemerintah daerah, hotel maupun agen perjalanan. Lokasi dari pusat informasi dan kandungan informasi yang dimiliki perlu disurvey dan dievaluasi untuk melihat kesesuaian lokasi, aksesibilitas, kompetensi informasi, bahasa dan informasi pendukung lainnya. Selain itu buku-buku petunjuk wisata yang membahas daerah studi perlu dikaji untuk melihat kesesuaian antara informasi yang diberikan dengan kondisi di lapangan.Pemerintah Kota Bima melalui Dinas Kebudayaan Dan Pariwisata telah menyediakan informasi pariwisata Kota Bima melalui brosur, spanduk maupun papan informasi yang diletakkan di fasilitas akomodasi maupun fasilitas umum terutama di fasilitas transportasi. Beberapa contoh informasi pariwisata dapat dilihat pada gambar berikut ini :

Fasilitas belanja baik sebagai daya tarik utama maupun pendukung perlu untuk disurvey dan dikaji secara mendalam. Umumnya wisatawan yang berkunjung ke suatu daerah mencari cenderamata untuk dibawa pulang ke tempat asalnya. Cenderamata ini bisa berbentuk kerajinan, hasil seni, pakaian, dan perhiasan. Di lain pihak di beberapa tempat wisatawan juga mencari barangbarang umum terutama barang-barang yang memiliki harga murah, barang yang mereka beli antara lain tembakau, minyak wangi, elektronik dan barang-barang lainnya. Selainbarang-barang yang bersifat cinderamata atau barang-barang umum yang dibawa pulang, dalam survey juga perlu diperhatikan penyediaan barangbarang sehari-hari kebutuhan wisatawan selama mereka melakukan kunjungan. Film, koran, majalah, air minum, obat-obat ringan merupakan fasilitas yang perlu disediakan di suatu daerah. Evaluasi untuk fasilitas ini dilakukan berdasarkan jenis dari fasilitas, barang dan pelayanan yang diberikan. Selain itu lokasi, aksesibilitas dan harga juga merupakan faktor- faktor yang perlu dikaji.Data Fasilitas Belanja yang tercatat pada Dinas Koperasi Perindustrian dan Perdagangan sebagai pendukung pengembangan pariwisata daerah di Kota Bima dapat dilihat pada tabel berikut

Tabel 6. Pasar Di Kota Bima

\begin{tabular}{|c|c|c|c|c|c|}
\hline No & Nama Pasar & Alamat Pasar & $\begin{array}{l}\text { Luas Pasar } \\
\text { (M2) }\end{array}$ & $\begin{array}{l}\text { Jumlah } \\
\text { Toko/Los }\end{array}$ & $\begin{array}{c}\text { Jumlah } \\
\text { Pedagang }\end{array}$ \\
\hline 1. & Pasar Raya & $\begin{array}{l}\text { Kelurahan Paruga Kec. } \\
\text { Rasanae Barat }\end{array}$ & 9.000 & $102 / 4$ & 563 \\
\hline 2. & Pasar Lama & $\begin{array}{l}\text { Kelurahan Sarae Kec. } \\
\text { Rasanae Barat }\end{array}$ & 2.300 & 118 & 225 \\
\hline 3. & Pasar Raba & $\begin{array}{l}\text { Kelurahan Rabangodu } \\
\text { Utara Kec. Raba }\end{array}$ & 1.192 & 45 & 112 \\
\hline 4. & Pasar Penaraga & $\begin{array}{l}\text { Kelurahan Penaraga } \\
\text { Kec. Raba }\end{array}$ & 3.500 & 30 & 55 \\
\hline 5 & Pasar Kumbe & Kelurahan kumbe Kec. & 1.595 & $24 / 2$ & 67 \\
\hline
\end{tabular}




\begin{tabular}{|c|c|c|c|c|c|}
\hline & & Rasanae Timur & & & \\
\hline 6. & Pasar Jatibaru & $\begin{array}{l}\text { Kelurahan Jatibaru Kec. } \\
\text { Asakota }\end{array}$ & 800 & 4 & 15 \\
\hline
\end{tabular}

Fasilitas penukaran uang untuk pariwisata intemasional mutlak diperlukan. Umumnya mereka membawa jumlah mata uang Rupiah yang terbatas, sementara pembayaran yang mereka lakukan adalahdalam rupiah, sehingga fasilitas ini menjadi penting bagi pengembangan pariwisata, dan ini perlu dikaji berdasarkanlokasi, jenis dan kualitas pelayanannya. Umumnya fasilitas seperti ini berada pada daerah- daerah umum seperti bandara, setasiun kereta api, terminal, dan pertokoan. Kemampuan fasilitas ini untuk dapat menerima berbagai mata uang dan kartu kredit juga harus dikaji dan dievaluasi. Umumnya wisatawan yang berkunjung enggan membawa uang dalam bentuk cash, mereka lebih menyenangi membawa kartu kredit yang lebih aman. Tuntutan seperti perlu disediakan oleh Daerah dengan melihat kesesuaiannya dengan pasar wisatawan yang ada. Fasilitas perbankan juga fasilitas penting untuk keperluan mereka melakukan transfer uang maupun cek perjalanan mereka, sehingga faktor ini juga patut untuk dipertimbangkan. Selain fasilitas di atas, Kota Bima juga memiliki sarana yang baik dalam aspek fasilitas kesehatan, keamanan, jas POS, jasa internet yang menjamu di Kota Bima, jasa paket perjalanan dan transportasi yang baik. Kota Bima memiliki banyak sekali event tahunan yang banyak menarik wisatawan nusantara maupun wisatawan mancanegara. Beberapa event tahunan yang ada di kota bima adalah sebagai berikut

Tabel 7. Event Pariwisata Kota Bima

\begin{tabular}{|c|c|c|c|}
\hline NO & NAMA EVENT & WAKTU & LOKASI \\
\hline 1 & 2 & 3 & 4 \\
\hline 1 & HANTA UA - PUA & $\begin{array}{l}\text { Perayaan Maulid Nabi } \\
\text { Muhammad SAW } \\
\text { (Tanggal 12 Rabiul Awal) }\end{array}$ & $\begin{array}{l}\text { Istana Kesultanan Bima dan } \\
\text { Kelurahan Melayu - Kec } \\
\text { Asakota Kota Bima }\end{array}$ \\
\hline & - Jikir Maulid & Tanggal 9 Rabiul Awal & Istana Kesultanan Bima \\
\hline & - Jikir Roko & Tanggal 10 Rabiul Awal & Kampung Melayu \\
\hline & - Kesenian Marawais & Tanggal 10 Rabiul Awal & Kampung Melayu \\
\hline & - Tarian Dani - Dana & Tanggal 10 Rabiul Awal & Kampung Melayu \\
\hline 2 & Festival Kuda & $\begin{array}{l}\text { HUT KOTA BIMA (10 } \\
\text { April) }\end{array}$ & \\
\hline & - Lomba Lukis Kuda & Tanggal 8 April & Museum Asi Mbojo \\
\hline & - Pawai Kuda & Tanggal 8 April & Kota Bima \\
\hline & - Pameran \& Kuliner Kuda & Tanggal 5 - 7 April & Lap Merdeka Kota - Bima \\
\hline & - Seminar / Dialog Budaya & Tanggal 4 April & Aula PEMKOT Bima \\
\hline & - Pacuan Kuda Tradisional & Tanggal 10 - 19 April & $\begin{array}{l}\text { Lap Pacuan Kuda Kota } \\
\text { Bima }\end{array}$ \\
\hline & $\begin{array}{l}\text { - Festival Seni Tradisional } \\
\text { Bima }\end{array}$ & Tanggal 2 - 7 April & Paruga Nae Kota Bima \\
\hline & $\begin{array}{l}\text { - Pawai Budaya Bima dan } \\
\text { Etnik (se - Nusantara) }\end{array}$ & Tanggal 9 April & Kota Bima \\
\hline & - Tarian Massal Tradisional & Tanggal 10 April & $\begin{array}{l}\text { Halaman Kantor Pemkot } \\
\text { Bima }\end{array}$ \\
\hline
\end{tabular}




\begin{tabular}{|c|c|c|c|}
\hline & Bima & & \\
\hline \multirow[t]{3}{*}{3} & $\begin{array}{l}\text { PAWAI dan FESTIVAL } \\
\text { BUDAYA }\end{array}$ & HUT KEMERDEKAAN RI & \\
\hline & $\begin{array}{l}\text { - Karnaval dan Pawai Budaya } \\
\text { Bima dan Etnik (se - } \\
\text { Nusantara) }\end{array}$ & Tanggal 15 Agustus & Kota Bima \\
\hline & $\begin{array}{l}\text { - Pemilihan Duta Wisata dan } \\
\text { Budaya Kota Bima }\end{array}$ & Tanggal 5 - 8 Agustus & Paruga Nae Kota Bima \\
\hline \multirow[t]{4}{*}{4} & $\begin{array}{l}\text { FESTIVAL \& PESTA } \\
\text { RAKYAT }\end{array}$ & SUMPAH PEMUDA & \\
\hline & $\begin{array}{l}\text { - Lomba Perahu Dayung } \\
\text { Tradisional }\end{array}$ & Tanggal 6 Oktober & Wadu Mbolo Teluk Bima \\
\hline & $\begin{array}{l}\text { - Lomba Renang Lintas Teluk } \\
\text { Bima }\end{array}$ & Tanggal 7 Oktober & Wadu Mbolo Teluk Bima \\
\hline & $\begin{array}{l}\text { - Pameran hasil kerajinan / } \\
\text { industri Rakyat (Kuliner dan } \\
\text { Kerajinan Tangan }\end{array}$ & Tanggal 7 - 9 Oktober & Kawasan Wisata Amahami \\
\hline \multirow[t]{4}{*}{5} & $\begin{array}{l}\text { FESTIVAL dan PAWAI } \\
\text { BUDAYA }\end{array}$ & HUT NTB & \\
\hline & - Pacuan Kuda Tradisional & Tanggal 15 - 23 Desember & Lap Pacuan Kuda Kota Bima \\
\hline & - Festival Kesenian Tradisional & $\begin{array}{l}\text { Tanggal } 04-08 \\
\text { Desember }\end{array}$ & Paruga Nae Kota Bima \\
\hline & - Bulan Apresiasi Budaya & Desember & Kab/Kota se NTB \\
\hline
\end{tabular}

Festival kuda menjadi unggulan Kota Bima. Kuda yang menjadi salah satu icon kuda merupakan bagian dari budaya masyarakat Mbojo. Ketangkasan menunggang kuda merupakan keterampilan yang menjadi bagian ceritacerita sejarah bima, yang masih terpelihara hingga kini. Diceritakannya bahwa sejak abad XII masehi, kuda asal bima sudah tersohor di nusantara. Saat itu, para pedagang dari berbagai penjuru datang membeli kuda bima, kemudian dijual di negeri asalnya untuk dijadikan tunggangan para raja, bangsawan, dan panglima perang. Raja-raja dan panglima perang kerajaan kediri, singosari, dan majapahit, dalam buku negarakertagama karangan empu prapanca, juga selalu memilih kuda bima untuk memperkuat armada kavalerinya. Diharapkan melalui kontes kuda yang kita laksanakan ini, tujuan untuk melestarikan dan mengembalikan pamor kuda bima sebagai potensi dan kebanggaan daerah dapat tercapai."Ingat kuda ingat bima, Ingat Bima Ingat Kuda" itulah harapan yang ingin diwujudkan dalam kegiatan festival kuda. Untuk parade atau pawai kuda dilaksanakan dengan Rute Jalan Soekarno - Hatta menuju Istana Bima dengan menampilkan pasukan berkuda Kesultanan Bima. Sementara untuk seminar tentang kuda akan dilaksanakan di Istana Bima Kegiatan ini dilatar belakangi oleh komitmen pemerintah memperkenalkan Potensi Bima, kuda sebagai icon bima serta pelestarian nilai budaya dan tradisi, ungkap Lalu Sukarsana.Sedangkan Pacuan Kuda atau Pacoa Jara sudah sangat lekat di masyarakat NTB dan sudah menjadi salah satu hiburan rakyat yang pasti selalu di adakan.Event pacuan kuda tradisional dengan joki-joki mungil dan lincah merupakan agenda rutin di Bima. 
Pembahasan hasil penelitian akan dibahas persepsi wisata terhadap pengembangan pariwisata syariah di Kota Bima. Adapun hasil penelitian terkait beberapa indikator penelitian diketahui: Persepsi wisatawan mengenai daya tarik wisata yang meliputi wisata alam, wisata budaya dan wisata buatan yang baik di obyek wisata kota bima berbasis syariah menunjukkan bahawa wisatawan yang memilih opsi Sangat Baik sebanyak 0.39\% atau 39 orang, memilih opsi Baik sebanyak $0.24 \%$ atau 24 orang. Hal ini menjadi penting bagi pengelola objek wisata kota bima bahwa dalam pengembangan objek wisata berbasis Syariah perlu memperhatikan daya tarik wisata yang meliputi wisata alam, budaya, dan buatan. Alasan responden sangat baik menginginkan pengembangan potensi Obyek Wisata Kota Bima Berbasis Syariah perlu memperhatikan pelestarian alam, budaya, dan buatan karena mereka melihat bahwa keunikan Kota Bima dibanding objek wisata lain seperti halnya di Bali adalah karena keasliannya. Jadi menurut mereka di Kota Bima tidak usah dibangun bangunan yang berlantai tinggi yang menyebabkan keaslian Kota Bima menjadi hilang. Sebagian besar responden menyukai keaslian dan suasana Kota Bima yang tidak terlalu ramai. persepsi wisatawan terkait dengan produk wisata yang ada di obyek wisata kota bima diketahui bahwa bahwa wisatawan yang memilih opsi Sangat Baik sebesar 0.24\% atau 24 orang, memilih opsi Baik sebesar $0.39 \%$ atau 39 orang, Cukup sebanyak $0.31 \%$ atau 31 orang, yang memilih opsi Tidak Baik sebesar $0.06 \%$ atau 6 orang. Untuk memajukan pariwisata Kota Bima ke depan, pemerintah daerah melalui Dinas terkait harus berusaha mengoptimalkan prodak wisata yang telah ada untuk mempopulerkan nama obyek wisata Kota Bima. persepsi wisatawan tentang kemudahan memperoleh makanan dan minuman yang halal diObjek Wisata Kota Bima diketahui bahwa wisatawan yang memilih opsi sangat baik sebesar $0.45 \%$ atau 45 orang, dan yang memilih opsi baik sebanyak $0.30 \%$ atau 30 orang. Hampir semua responden yang berkunjung ke obyek wisata Kota Bimaberpresepsi sangat baik mengenaik makanan dan minuman yang halal di obyek wisata dikota bima. Modal ini sangat penting bagi pengembangan Objek Wisata Kota Bima berbasis syariah untuk ke depannya. persepsi wisatawan mengenaipertunjukan seni budaya yang diselenggarakan tidak bertentangan dengan kaidah syariah yang baik diperoleh hasil wisatawan yang memilih opsi Sangat baik sebesar $0.43 \%$ atau 43 orang, memilih opsi Baik sebanyak $0.34 \%$ atau 34 orang, opsi Cukup Baik sebanyak $0.18 \%$ atau 18 orang dan yang memilih opsi Tidak Baik sebesar 0.02\% atau 2 orang. Hal ini perlu menjadi perhatian khusus dalam pengembangan wisata berbasis syariah di kota bima. persepsi wisatawan tentangpenyediaan tempat ibadah yang layak dan baik dilengkapi dengan sarana bersuci yang memadai di obyek wisata kota bima diketahui bahwa responden yang memilih opsi baik sebesar $0.35 \%$ atau 35 orang, responden yang yang menyatakan sangat baik sebanyak $0.35 \%$ atau 35 orang dan yang menyatakan cukup sebanyak $0.27 \%$ dari total responden. Hal ini nampak terlihat bahwa objek wisata kota bima perlu meningkatkan lagi ketersediaan sarana ibadah dan bersuci yang layak bagi setiap wisatawan yang berkunjung. Responden yang menyatakan sangat tidak baik hanya $0.01 \%$. Hasil ini tetap menjadi perhatian pengelola agar dapat meningkatkan lagi kelayakannya. persepsi wisatawan tentang sanitasi dan kebersihan lingkungan yang terjaga dengan baik di obyek wisata kota bima diketahui bahwa hampir mayoritas wisatawan yang berkunjung di obyek wisata kota bima mengetakan bahwa kebersihan di obyek cukup baik Hal ini dibuktikan dengan jawaban responden yang memilih opsi cukup baik sebesar $0.31 \%$ atau 31 orang 
dan yang memilih opsi baik sebanyak $0.25 \%$ atau 25 orang serta yang mengatakan tidak baik sebanyak $0.21 \%$. dan responden yang menyatakan sangat baik hanya $0.19 \%$ atau 19 orang. Hal ini tentu menjadi hal yang perlu di perhatikan lagi bagi pengembangan objek wisata berbasis syariah karena adanya daya dukung dari lingkungan sangat di perlukan bagi pengembangan wisata kota bima. persepsi wisatawan terhadap ketersediaan tempat ibadah yang layak di hotel dan tempat menginap lainnya di kota bima diketahui bahwa Hampir sebagian besar wisatawan mengatakan bahwa ketersediaanya sangat baik. Hal ini dibuktikan dengan jawaban wisatawan yang memilih opsi Sangat baik sebesar $0.45 \%$ atau 45 orang, memilih opsi Baik dan Cukup baik sebanyak $0.23 \%$ atau 23 orang, opsi tidakbaik sebanyak $0.06 \%$ atau 6 orang dan yang memilih opsi sangat tidak baik sebesar $0.03 \%$ atau 3 orang. Dengan adanya jawaban responden yang menganggap bahwa tingkat ketersediaan yang sangat baik, maka hal ini penting bagi pengembangan objek wisata berbasis syariah di kota bima karena pentingnya daya dukung ketersediaan tempat ibadah di hotel bagi pengembangan ke depannya. Untuk mengetahui persepsi wisatawan terhadapketersediaan sarana bersuci yang layak di hotel dan tempat menginap lainnya di kota bima diketahui bahwa wisatawan yang mengatakan ketersediaan sarana bersuci di hotel dan tempat menginap lainnya yaitu baik sebesar $0.38 \%$ atau 38 orang, yang memilih opsi cukup baik sebanyak $0.28 \%$ atau 28 orang, opsi sangat baik sebanyak $0.25 \%$ atau 25 orang. Opsi tidak baik sebesar $0.06 \%$ atau 6 orang dan sangat tidak baik hanya sebesar $0.03 \%$ atau sebanyak 3 orang. Keberadaan sarana bersuci yang layak, sangat penting bagi para wisatawan. Hal ini juga, harus menjadi perhatian pengelola objek wisata dalam pengembangan pariwisatanya agar wisatwan yang berkunjung merasa nyaman berkunjung ke kota bima dengan layanan yang baik dan nyama. persepsi wisatawan terhadap ketersiapan restoran yang menyediakan makanan dan minuman yang terjamin kehalalanya dengan sertifikasi halal diketai bahwa persepsi sangat siap sebesar $0.38 \%$ atau sebanyak 38 orang, dan siap sebanyak 37 orang. Cukup siap sebanyak 23 orang atau sebesar $0.23 \%$, tidak siap $0.02 \%$ atau sebanyak 2 orang saja. Ini membuktikan bahwa kota bima dapat di katakan sangat siap untuk restoran-restoran yang menyediakan makanan dan minuman yang terjamin kehalalanya dengan sertifikasi halal dari MUI. persepsi wisatawan terhadap ketersiapan sanitasi dan kebersihan lingkungan restoran dan penyedia jasa makanan dan minuman yang terjaga dengan baik di kota bima diketahui bahwa persepsi sangat siap sebesar $0.38 \%$ atau sebanyak 38 orang, dan siap sebanyak 33 orang atau sebesar $0.33 \%$. Cukup siap sebanyak 16 orang atau sebesar $0.16 \%$, tidak siap $0.02 \%$ atau sebanyak 2 orang dan sangat tidak siapa sebesar $0.01 \%$ atau hanya 1 orang saja. Ini membuktikan bahwa kota bima dapat di katakan sangat siap untuk ketersiapan sanitasi dan kebersihan lingkungan restoran dan penyedia jasa makanan dan minuman yang terjaga dengan baik di kota bima. Untuk mengetahui persepsi wisatawan terhadap ketersiapan tempat hiburan malam di kota bima yang tidak mengandung unsur pornoaksi dan pornografi dapat di lihat dari data hasil penelitian menunjukkan bahwa persepsi sangat siap memilki persepsi terbanyak yaitu 33 orang atau sebesar $0.33 \%$. dan persepsi siap dan tidak siap berada pada angka yang sama yaitu $0.21 \%$ atau sebanyak 21 orang. Cukup siap sebesar $0.18 \%$ dan sangat tidak siap hanya sebesar $0.07 \%$ atau sebanyak 7 orang. Dari data penelitian di atas, kota bisa dapat di katakan sangat siap dengan adanya tempat hiburan malam yang tidak mengandung unsur pornoaksi dan pornografi. Namun hal ini, harus terus di perhatikan dan di 
pantau dengan baik, agar tidak menjadi kendala dalam upaya pengembangan wisata berbasis syariah di kota bima. Untuk untuk mengetahui bagaimana ketersiapan sarana yang memudahkan untuk beribadah di tempat hiburan malam di kota bima diketahui persepsi cukup siap dan tidak siap berada pada angka yang sama yaitu sebesar $0.21 \%$ atau sebanyak 21 orang. Kemudian di ikuti dengan persepsi sangat siap sebesar $0.20 \%$ atau sebanyak 20 orang, siap sebanyak 19 orang atau sebesar $0.19 \%$ dan persepsi sangat tidak siap sebesar $0.18 \%$ atau sebanyak 118 orang. Melalui data di atas, untuk ketersiapan sarana yang memudahkan untuk beribadah di tempat hiburan malam, perlu di perhatikan lagi, karena ketersiapan sarana beribadah menjadi faktor pendukung dalam upaya pengembangan wisata berbasis syariah di kota bima. Pengemasan paket wisata yang baik, akan menjadi penarik perhatian bagi wisatawan yang ingin melakukan perjalanan wisata. Baik, buruk, bagus dan tidaknya objek wisata ataupun destinasi wisata yang akan di kunjungi akan terlebih dahulu di gambarkan melalui paket wisata yang akan di tawarkan. Hal itu akan memberikan opini/persepsi yang positif dari wisatawan diketahui bahwa wisatawan yang berpresepsi siap pada angkat tertinggi yaitu sebesar $0.43 \%$ atau sebanyak 43 orang mengatakan siap, kemudian sangat siap 25 orang atau $0.25 \%$ dan cukup siap sebesar $0.22 \%$ atau sebanyak 22 orang. Wisatawan yang berpresepsi tidak siap hanya 6 orang dan sangat tidak siap sebesar $0.04 \%$ atau sebanyak 4 orang saja. Dari data di atas dapat di lihat bahwa ketersiapan dari biro perjalanan wisata sudah bagus. Hal ini sangat mendukung dalam pengemasanpengemasan paket wisata yang sesuai dengan kriteria pariwisata syariah yang akan di berlakukan di kota bima. Penilain dari wisatawan terhadap pramuwisata perlu di perhatikan guna memberikan pelayanan yang lebih baik kepada wisatawan. Dalam upaya pengembangan wisata syariah ini perlu di perhatikannya juga apakah pramuwisata memahami dan mampu melaksanakan nilai-nilai syariah dalam menjalankan tugasnya. Hasil penelitian menunjukkan pada aspek ini penilaian wisatawan terbanyak pada penilaian baik yaitu 38 orang atau sebesar $0.38 \%$, cukup baik $0.31 \%$ dan sangat baik sebesar $0.26 \%$ atau sebanyak 26 orang, sedangkan penilaian tidak baik hanya 5 orang atau sebesar $0.05 \%$ saja. Dari penilaian ini, mendapat di lihat bahwa pramuwisata di kota bima dapat memahami dan mampu menjalankan nilainilai syariah dalam melaksanakan tugasnya. Sebagai seorang pramuwisata, penampilan merupakan hal yang sangat diperhatikan, karena penampilanlah yang pertama kali yang akan di lihat dan di nilai oleh wisatawan. Dari penampilan sudah bisa di pastikan, apakah akan memberikan kesan yang baik atau tidak. Dalam upaya pengembangan wisata berbasis syariah, tentunya bagi pramuwisata harus berpenampilan sopan yang tidak bertentangan dengan nilai etika islam. Untuk melihat bagaimana penilaian dari wisatawan diketahui bahwa Penilaian terbanyak terdapat pada penilaian baik yaitu $0.38 \%$, kemudian cukup baik $0.36 \%$ atau sebannyak 36 orang, sangat baik 24 orang atau $0.24 \%$ dan tidak baik hanya 2 orang atau $0.02 \%$ saja. Dari data di atas, pramuwisata di kota bima telah berpenampilan yang sopan dan menarik sesuai dengan nilai etika islam. Dan hal ini perlu di jaga ataupun di tingkatkan lagi. Dalam upaya pengembangan wisata berbasis syariah, hal ini perlu di perhatikan, agar tidak bertentangan dengan nilai-nilai etika dalam islam. Kemudahan akses informasiwisata perlu di perhatikan. Keberadaan sebuah objek wisata akan bisa di kenal, melalui kmudahan akses informasi. Hal tersebut akan sangat membantu dalam mempromosikan objek wisata yang tersebut. Dan hal tersebut akan mempermudah wisatawan dalam 
mendapatkan referensi wisata. Bagaimana penilaian wisatawan terhadap kemudahan akses informasi wisata syariah/halal di kota bima diketahui bahwa penilaian dari wisatawan yang tertinggi pada pada penilaian cukup baik yaitu $0.36 \%$ kemudian di ikuti dengan penilaian $0.32 \%$ dan sangat baik sebesar $0.30 \%$ atau sebanyak 30 orang. Dan tidak baik hanya sebesar $0.02 \%$ atau sebanyak 2 orang saja. Dari segi kemudahan akses informasi pariwisata di kota bima sudah baik. Dan hal ini perlu di pertahankan dan di kembangkan lagi, guna kemajuan pariwisata di kota bima. Kemudahan dalam menjangkau objek wisata, sangat membantu dalam mempromosikan objek kota bima, terutama untuk wisatawan itu sendiri. Dengan kemudahan tersebut akan memberikan penilaian yang baik dari wisatawan, dan bahkan bisa membuat wisatawan untuk datang mengunjungi kembali objek wisata tersebut. Bagaimana penilaian dari wisatawan terhadap kemudahan dalam menjangkau objek wisata di kota bima diketahui bahwa penilaian tertinggi pada posisi sangat baik yaitu sebanyak 40 orang atau sebesar $0.40 \%$ kemudian di ikuti dengan penilaian cukup baik yaitu sebesar $0.32 \%$ atau sebanyak 32 orang dan baik sebanyak 26 orang dan tidak baik hanya sebesar $0.02 \%$ atau sebanyak 2 orang saja. Dapat di simpulkan bahwa penilaian dari wisatawan terhadap kemudahan dalam menjangkau objek wisata di kota bima sangat baik.

Hasil analisis SWOT telah
dilaksanakan terhadap prospek pengembangan potensi obyek wisata Kota Bima sebagai obyek wisata Berbasis Syariah dapat diketahui bahwa Kekuatan yang dimiliki adalah 1). Kota Bima memiliki beragam potensi untuk menjadi salah satu destinasi wisata syariah yang strategis karena sejarah ke islaman yang sangat kuat, dan adat istiadat berpegang teguh dengan islam, serta atraksi wisata alam, budaya, religi serta minatkhusus; 2). Kota Bima sudah memiliki kelengkapan untuk menunjang pengembangan wisata berbasis syariah seperti hotel syariah, bank syariah, pegadaian syariah serta didukung oleh kultur budaya khas muslim dan penerimaan masyarakat; 3). Syariat Islam atauproduk halal sudah menjadi bagian dalam kehidupan sehari-hari masyarakat Kota Bima; 4). Kota Bima terus mengadakanevent-event tahunan yang berbasis religi dantradisi; 5). Kota Bima memiliki potensi sebagai destinasi transit tourism karena berada pada jalur emas wisata Indonesia, yaitu jalur Bali-Lombok dan Lombok - Labuan Bajo Flores dengan Pulau Komodonya. Kelemahan yang dimiliki adalah: 1) Sebagian besar pelaku industri di kota bima belum mencantumkan label halal yang bersertifikasi dariMPU; 2). Belum siapnya SDM Kota Bima dalam mengembangkan wisata syariah terutama dalam pelayanan(hospitality), misalnya: pramuwisata yang belumsepenuhnya menerapkan prinsip-prinsip islami dalam mendampingi wisatawan, para supir travel dan bus. Baik dari aspek tingkat kebersihan, kerapian dan ketertiban,seperti kebiasaan meneroboslampu, merah; 3). Pandangan negatif dari masyarakat/tokoh masyarakat/ulama bahwa pariwisata hanya menekankan pada sun, sand, sea, smile, and sex dan 4).Beberapa keluhan wisatawan saat berkunjung ke Kota Bima adalah masih kurangnya fasilitas pariwisata, seperti MCK serta mushalla, Tempat Parkir harga barang dan makanan di pasar belum standar, karena di setiap lokasi berbeda-beda harganya. Peluang yang dimiliki adalah 1). Indonesia merupakan negara dengan penduduk muslim terbesar di dunia dan banyak objek wisata alam bernuansa syariah seperti situs- situs peninggalan kerajaan Islam dan pusat pesantren Islam; 2). Potensi devisa yang bisa dihasilkan negara dari wisata syariah juga cukup besar; 3). Industri halal dan kesadaran akan pentingnya produk halal terus bertumbuh, ditandai dengan semakin meningkatnya permintaan 
sertifikasi halal ke badan LPPOM MUI; 4). Kelas menengah di Indonesia disinyalir kian meningkat. Hal ini berdampak pada tingkat konsumsi secara signifikan, khususnya dari kelasmenengah untukmembelanjakan uangnya terutama di sektor-sektor konsumtif seperti kuliner, fashion dan gaya hidup. Ancaman dalam pengembangan wisata syariah di Kota Bima adalah 1). Belum adanya kejelasan konsep wisata syariah yang dapat diterapkan di Kota Bima dan di Indonesia pada umumnya; 2). Perkembangan Wisata syariah di Indonesia masih kalah cepat dibanding negara lain yang sudah lebih dulu menggarap industri wisata syariah; 3). Belum adanya regulasi dalam bentuk perundang- undangan secara nasional terkait wisata syariah.Birokrasi yang lambat menjadi ciri khas Indonesia, ikut memperlambat pengembangan wisata syariah.Belum adanya regulasi juga membuat pelaku usaha gamang dalam menerapkan wisata syariah; 4).Promosi wisata yang berkaitan dengan wisata syariah belum begitu segencar wisata umum/konvensional dan 5).Kurangnya sosialisasi dan koordinasitentang wisata syariah di Indonesia.Adapun strategi yang dapat dilakukan untuk mengembangkan potensi wisata syariah di Kota Bima adalah 1). Pengemasan paket wisata syariah yang lebih menarik sesuai target pasar. Misalnya dengan paket wisata sejarah dan religi;

2).Mengembangkan fasilitas- fasilitas pariwisata berstandar syariah seperti hotel, restoran, spa; 3).Memberikan insentif/ donasi dari pemerintah baik pusat maupun daerah, misalnya kemudahan pengajuan dan pembiayaan gratis sertifikasi halal, penyediaan shuttle bus gratis khusus bagi wisatawan untuk mengantar ke setiap atraksi wisata; 4).SDM: Pembinaan kelompok sadar wisata (Pokdarwis) halal/muslim friendly, , mengadakan seminar dengan tema "kesehatan dansyariah", dan adanya sanksi bagi pelaku usaha yang tidak mempunyai sertifikasi halal; 5). Penciptaan sistem sertifikasi produk halal yang mapan dan transparan di bawah MPU Kota Bima; 6).Inventarisasi/audit/quick assessmentsetiapdestinasi,produk, restoran yang diberikan sertifikasi halal, kesiapan sarana dan prasarana, serta unsur pendukung lain. serta kebutuhan wisata syariah secara konkret di Kota Bima; 7). Meningkatkan koordinasi dan sosialisasi wisata syariahdenganmenggandeng kalangan masyarakat dan lembaga lain; 8).Melakukan kerja sama dengan negara lain dan lembaga internasional yang memiliki perhatian dalam mengembangkan wisata syariah untukmengembangkan promosi bersama sehingga Kota Bima menjadi wisata tingkat dunia; 9). Tetap memperhatikan dan mempertahankan karakteristik keaslian dan keunikan Kota Bima; 10).Peningkatan promosi wisata dan penyediaan informasiwisata berbasis teknologi komunikasi yang mengerti kebutuhan wisatawan (customer-friendly); 11).Mendorong para pelaku bisnis wisata di kota bima untuk dapat menggaetpasar wisatawan dari negara yang mayoritas muslim.

\section{KESIMPULAN}

Hasil penilaian wisatawan terhadap potensi objek wisata syariah di Kota Bima sebagaian besar menyatakan bahwa Kota Bima memiliki potensi dan kesiapan untuk mnjadi destinasi wisata syariah dengan berbagai potensi yang dimiliki, seperti objek wisata alam, wisata budaya, sarana dan prasarana pariwisata, serta dukungan dari pemerintah daerah dan masyarakat lokal Kota Bima. Kota Bima memiliki beragam potensi untuk menjadi salah satu destinasi wisata syariah yang strategis karena sejarah ke islaman yang sangat kuat, dan adat istiadat berpegang teguh dengan islam, serta atraksi wisata alam, budaya, religi serta minatkhusus.Kota Bima sudah memiliki kelengkapan untuk menunjang pengembangan wisata berbasis syariah seperti hotel syariah, bank syariah, 
pegadaian syariah serta didukung oleh kultur budaya khas muslim dan penerimaan masyarakat.Syariat Islam atauproduk halal sudah menjadi bagian dalam kehidupan sehari-hari masyarakat Kota Bima. Kota Bima terus mengadakanevent-event tahunan yang berbasis religi dantradisi. Kota Bima memiliki potensi sebagai destinasi transit tourism karena berada pada jalur emas wisata Indonesia, yaitu jalur Bali-Lombok dan Lombok - Labuan Bajo Flores dengan Pulau Komodonya. Tetapi di sisi lain sebagian besar pelaku industri di kota bima belum mencantumkan label halal yang bersertifikasi dariMPU. Selain itu belum siapnya SDM Kota Bima dalam mengembangkan wisata syariah terutama dalam pelayanan(hospitality), misalnya: pramuwisata yang belumsepenuhnya menerapkan prinsip-prinsip islami dalam mendampingi wisatawan para supir travel dan bus, baik dari aspek tingkat kebersihan, kerapian dan ketertiban,seperti kebiasaan menerobos lampu merah.

\section{DAFTAR PUSTAKA}

Alamsyah, I. E. (2018, Juni 12).Wisata

Syariah Butuh Dukungan Pemda:

Mahaka Group. (I. Kelana, Penyunting) DipetikAgustus

26, 2018, dari

republikaonline.

Alim, Haidar Tsany ; Andi Okta Riansyah; Karimatul Hidayah; Ikhwanul Muslim; Adityawarman. 2016. Analisis Potensi Pariwisata Syariah Dengan Mengoptimalkan Industri Kreatif Di Jawa Tengah Dan Yogyakarta.Jogyakarta. Universitas Diponegoro.

Chookaew, S., chanin, O., Charatarawat, J., Sriprasert, P., \& Nimpaya, S. (2015). Increasing Halal Tourism Potential at Andaman Gulf in. Journal of Economics, Business and Management, III (7), 277279.

Indonesia Kreatif.(2018, Januari 24).Apa Itu Ekonomi Kreatif. Dipetik Agustus 28, 2018, dari Indonesia Kreatif: http://gov.indonesiakreatif.net/ ekonomi-kreatif/

Kementrian Ekonomi dan Pariwisata Republik Indonesia. (2013). Undang-undang No 10 Tahun 2009.Jakarta: Kemenparekraf RI.

Kovjanic, G. (2018). Islamic Tourism as a Factor of the Middle East.Turizam, 18 (1)

Moira, P., Mylonopoulos, D., \& Kontoudaki, A. (2017). The Management of Tourist's Alimentary Needs by the Tourism Industry. International Journal of Culture and Tourism Research,5 (1), 129-140.

Muhdar. (2018). Kemitraan Stakeholders Pariwisata Dalam Mendukung Pengembangan Wisata Syariah di Kota Bima. Bima. UP2M STISIP Mbojo Bima

Munirah, L., \& Ismail, H. N. (2017). Muslim Tourists' Typologi in Malaysia: Perspectives and Challenges. Proceedings of the Tourism and Hospitality International Conference. Malaysia: Department of Urban and Regional Planning, Faculty of Built Environment,.

Priyadi, Unggul; Yazid; Eko Atmaji. (2018). Potensi Pengembangan Pariwisata Berbasis Syariah di Kabupaten Sleman. Jogyakarta

Sahida, W., Rahman, S. A., Awang, K., \& Man, Y. C. (2011). The 
Implementation of Halalh

ComplianceConceptHotel:DePalm

a.2ndInternationalConferenceonH umanities,Historical and Social Sciences.17, pp. 138-142. Singapore: IACSIT

Sutomo \&Sapudin, A., Adi, F (2018). Analisis Perbandingan Hotel dan Pariwisata Syariah dengan Konvensional. Bogor: Magister Manajemen Syariah IPB.

Sucipto.(2018, Agusuts 11).Peluang Wisata Syariah: Mahaka Group. Dipetik Agustus 26, 2018, dari Republika Online: http://www.republika.co.id/berita/ koran/opinikoran/14/08/11/na4ooc19peluang-wisata-syariah 